\title{
Human Beta-2 Adrenoceptor Gene Polymorphisms Are Highly Frequent in Obesity and Associate with Altered Adipocyte Beta-2 Adrenoceptor Function
}

\author{
Valérie Large, ${ }^{\star}$ Lena Hellström, ${ }^{\star}$ Signy Reynisdottir, ${ }^{\star}$ Fredrik Lönnqvist, ${ }^{\star}$ Per Eriksson, ${ }^{\S}$ Lars Lannfelt, ${ }^{\ddagger}$ and Peter Arner* \\ ${ }^{*}$ Department of Medicine, ${ }^{\ddagger}$ Department of Geriatric Medicine, and Research Center, Karolinska Institute, Huddinge University Hospital, \\ Stockholm, Sweden; and ${ }^{\S}$ King Gustav V Research Institute, Karolinska Hospital, Stockholm, Sweden
}

\begin{abstract}
Catecholamines play a central role in the regulation of energy expenditure, in part by stimulating lipid mobilization through lipolysis in fat cells. The beta- 2 adrenoceptor (BAR-2) is a major lipolytic receptor in human fat cells. To determine whether known polymorphisms in codons 16, 27, and 164 of this receptor play a role in obesity and subcutaneous adipocyte BAR-2 lipolytic function, we investigated a group of 140 women with a large variation in body fat mass. Only the polymorphisms in codons 16 and 27 were common in the study population. The Gln27Glu polymorphism was markedly associated with obesity with a relative risk for obesity of $\sim 7$ and an odds ratio of $\sim 10$. Homozygotes for Glu27 had an average fat mass excess of $20 \mathrm{~kg}$ and $\sim 50 \%$ larger fat cells than controls. However, no significant association with changes in BAR-2 function was observed. The Arg16Gly polymorphism was associated with altered BAR-2 function with Gly16 carriers showing a fivefold increased agonist sensitivity and without any change in BAR-2 expression. However, it was not significantly linked with obesity. These findings suggest that genetic variability in the human BAR-2 gene could be of major importance for obesity, energy expenditure, and lipolytic BAR-2 function in adipose tissue, at least in women. (J. Clin. Invest. 1997. 100: 3005-3013.) Key words: fat cell • DNA • lipolysis • restriction fragment length polymorphism $\bullet$ polymerase chain reaction
\end{abstract}

\section{Introduction}

It is well established that obesity is under strong genetic influence, with up to $40 \%$ of the variation in body fat content being attributed to genetic factors (1). Several of the genes causing obesity in laboratory animal models have been characterized recently (2). Much less is known about genes involved in human obesity (3), because the obese phenotype in humans is not only determined by a number of different genes but also by a large number of environmental factors.

Genes that are involved in the regulation of catecholamine function may be of particular importance for human obesity

Address correspondence to Peter Arner, M.D., Center for Metabolism and Endocrinology, M63, Karolinska Institute at the Department of Medicine, S-14186 Huddinge University Hospital, Stockholm, Sweden. Phone: 46-8-58582342; FAX: 46-8-58587223.

Received for publication 23 May 1997 and accepted in revised form 24 September 1997.

J. Clin. Invest.

(C) The American Society for Clinical Investigation, Inc. 0021-9738/97/12/3005/09 \$2.00

Volume 100, Number 12, December 1997, 3005-3013

http://www.jci.org because of the central role they have in energy expenditure both as hormones and neurotransmitters. A key factor in the energy balance is the mobilization of lipids through lipolysis in fat cells (4). All three known beta adrenoceptor (BAR) ${ }^{1}$ subtypes can promote lipolysis in human adipose tissue in vivo (5, $6)$. Recently, a coding mutation in the BAR-3 gene was reported which associated with rapid weight gain and some metabolic complications to obesity (7-9). However, this genetic variation may be of minor importance in obesity since in most of the populations studied its frequency is not increased in obesity $(10,11)$. Furthermore, little or no difference in phenotypic characteristics exists between carriers and noncarriers of this polymorphism (10-12). This mutation fails to cause a detectable change in function in both native human fat cells (13) and in recombinant cells (14).

In a number of elegant studies, Liggett and colleagues have described three polymorphisms in the human BAR-2 gene that have been studied in relation to asthma. These include the rare Thr164Ile variant and two common Arg16Gly and Gln27Glu variants (15). Thr164, Arg16, and Gln27 are considered as the "wild" forms. When these are substituted for Ile164, Gly16, or Glu27, the function of the BAR-2 is markedly altered in recombinant cells $(16,17)$. Even if in most of the studies none of these missense mutations were more prevalent in asthma patients than in normal control subjects, the Gly16 and Glu27 variants have been shown to be associated with altered phenotypic characteristics in certain forms of asthma $(18,19)$. It is yet unknown whether these genetic variants are associated with other clinical disorders or if they are linked to changes in native human BAR-2 function.

In this study, we investigated whether the previously described human BAR-2 gene polymorphisms are associated with obesity and whether they are of functional importance for the human fat cell in a study population consisting of 140 women with a large variation in body mass index (BMI).

\section{Methods}

\section{Subjects}

The study group consisted of 140 nonrelated subjects who were not receiving any medication. Subjects were recruited in two different ways. One group included 85 women who were either healthy, nonobese volunteers or otherwise healthy subjects referred to the Department of Medicine because of uncomplicated obesity. BMI ranged from 17.8 to $52.5 \mathrm{~kg} / \mathrm{m}^{2}$ in this group. The second group consisted of 55 women with a large variation in body weight (BMI $18.4-60.0 \mathrm{~kg} / \mathrm{m}^{2}$ ), who were referred to the Department of Surgery for surgical treatment of obesity by gastric banding, uncomplicated gallstones, or abdominal hernias. These two groups did not differ statistically in any of the following measures, including age, BMI, waist-to-hip ratio (WHR),

1. Abbreviations used in this paper: $\mathrm{BAR}$, beta adrenergic receptor; BMI, body mass index; WHR, waist-to-hip ratio. 
fat cell volume, and fasting plasma levels of glucose and insulin. Therefore, the two cohorts were considered as one uniform group in all subsequent analyses. Both groups were investigated at the hospital after an overnight fast. Height and body weight were first determined. Thereafter, a venous blood sample was obtained from an antecubital vein for extraction of DNA and the determination of plasma glucose by the hospital's routine chemistry laboratory and plasma insulin at our own laboratory by a commercial radioimmunoassay (Pharmacia-Upjohn, Uppsala, Sweden). An abdominal subcutaneous fat biopsy was obtained under local anesthesia from the "medicine" subjects and in connection with open surgery from the "surgery" subjects, exactly as described previously (20). We have demonstrated that the adrenoceptor function and lipolysis do not differ in fat cells obtained through these two different procedures (20). Between $200 \mathrm{mg}$ and $1 \mathrm{~g}$ of fat was obtained and used for immediate analysis. To determine the frequency of the investigated mutations, the material was divided into nonobese (58 subjects) and obese ( 82 subjects) groups. A BMI of $27 \mathrm{~kg} / \mathrm{m}^{2}$ was used as the cut-off point. The nonobese subjects had a mean BMI of $23.0 \pm 0.3 \mathrm{~kg} / \mathrm{m}^{2}$ and a mean WHR of $0.87 \pm 0.01$ in comparison with $39.3 \pm 0.8 \mathrm{~kg} / \mathrm{m}^{2}$ and $0.95 \pm 0.01$, respectively, for the obese subjects. Both groups were comparable in age; the mean of the normal weight subjects being $38.9 \pm 0.8 \mathrm{yr}$ and of the obese group $37.7 \pm 1.3 \mathrm{yr}$. The body fat content was determined by a formula derived from age, sex, and BMI (21). The body fat was also measured on 34 subjects, using a body fat analyzer (model TBF-305; Tanika, Tokyo, Japan). The BMI was uniformly distributed between 25 and $50 \mathrm{~kg} / \mathrm{m}^{2}$ in these subjects. There was an excellent correlation between both methods of BMI determination $(r=0.92$, slope $=1.3)$. The subjects were informed in detail about the investigation and their consent was obtained. The study was approved by the hospital's Ethical Committee.

\section{Analysis of RFLP}

Genomic DNA was extracted from leukocytes in samples of whole blood by digestion with proteinase $\mathrm{K}$ followed by phenol/chloroform extraction. PCR amplification was performed on an automated apparatus (PTC-200; SDS Co., Falkenberg, Sweden).

PCR amplification of the DNA segment containing codon 27 of the $B A R-2$ gene. PCR amplification of the DNA segment containing codon 27 of the BAR-2 gene was carried out in a volume of $26 \mu \mathrm{l}$ containing 300-500 ng DNA, $0.38 \mathrm{mM}$ of each deoxynucleoside triphosphate, $10 \%$ buffer $\left(100 \mathrm{mM}\right.$ Tris- $\mathrm{HCl}, 15 \mathrm{mM} \mathrm{MgCl}_{2}, 500 \mathrm{mM} \mathrm{KCl}$, $\mathrm{pH} 8.3), 10 \%$ DMSO, 20 pmol of each primer, and 0.13-0.63 U of Taq DNA polymerase. The forward primer was 5'-GGCCCATGACCAGATCAGCA-3' and the reverse primer was 5'-GAATGAGGCTTCCAGGCGTC-3'. PCR was started with denaturation at $94^{\circ} \mathrm{C}$ for 4 min, followed by 30 cycles of denaturation $\left(94^{\circ} \mathrm{C}, 1 \mathrm{~min}\right)$, annealing $\left(63^{\circ} \mathrm{C}, 1 \mathrm{~min}\right)$, and extension $\left(72^{\circ} \mathrm{C}, 1 \mathrm{~min}\right)$, with a final extension at $72^{\circ} \mathrm{C}$ for $10 \mathrm{~min}$. The PCR product size from these primers is $353 \mathrm{bp}$. The amplified product was digested at $37^{\circ} \mathrm{C}$ for $1 \mathrm{~h}$ with $0.4 \mathrm{U}$ of Ita I. The fragments were resolved on a $2 \%$ ultra-pure DNA agarose gel with Tris-acetate EDTA (40 mM Tris-acetate, $2 \mathrm{mM}$ EDTA) buffer and visualized under ultraviolet illumination after staining with ethidium bromide. This digestion produced fragments of the following sizes: 27, 55, 97, and 174 bp in Gln27 homozygotes; 27, 55, 97, 174, and 229 bp in Gln27Glu27 heterozygotes; and 27, 97, and 229 bp in Glu27 homozygotes. The 27-bp fragment was too small to be resolved on the gel.

$P C R$ amplification of the DNA segment containing codon 16 of the $B A R$-2 gene. PCR amplification of the DNA segment containing codon 16 of the BAR-2 gene was carried out the same way as for the codon 27 but using 5'-CTTCTTGCTGGCACGCAAT-3' as the forward primer and 5'-CCAGTGAAGTGATGAAGTAGTTGG-3' as the reverse primer. The other differences included using an annealing temperature of $56^{\circ} \mathrm{C}$ and excluding DMSO. The PCR product size from these primers is $201 \mathrm{bp}$. The forward primer is complementary to the BAR-2 DNA sequence except for one nucleotide which permits the creation of a BsrDI restriction site. The amplified product was digested at $60^{\circ} \mathrm{C}$ for $1 \mathrm{~h}$ with $2 \mathrm{U}$ of BsrDI. The fragments were re- solved on a 3\% Meta-Phor agarose gel with Tris-borate EDTA (89 mM Tris, $89 \mathrm{mM}$ boric acid) buffer and visualized under ultraviolet illumination after staining with ethidium bromide. This digestion produced fragments of the following sizes: 14, 56, and $131 \mathrm{bp}$ in Arg16 homozygotes; 14, 23, 56, 108, and 131 bp in Arg16Gly16 heterozygotes; and $14,23,56$, and 108 bp in Gly16 homozygotes.

PCR amplification of the DNA segment containing codon 164 of the BAR-2 gene. PCR amplification of the DNA segment containing codon 164 of the BAR-2 gene was carried out the same way as for codon 27 with 5'-GGACTTTTGGCAACTTCTGG-3' as the forward primer, $5^{\prime}$-ACGAAGACCATGATCACCAG- $3^{\prime}$ as the reverse primer, and an annealing temperature of $55^{\circ} \mathrm{C}$. The PCR product size from these primers is $358 \mathrm{bp}$. The amplified product was digested at $37^{\circ} \mathrm{C}$ for $1 \mathrm{~h}$ with $2 \mathrm{U}$ of MnlI. The fragments were resolved on a $2 \%$ ultra-pure DNA agarose gel with Tris-acetate EDTA (40 mM Tris acetate, 2 mM EDTA) buffer and visualized under ultraviolet illumination after staining with ethidium bromide. This digestion produced fragments of the following sizes: 38, 114, and 206 bp in Thr164 homozygotes; 38, 114, 206, and 320 bp in Thr164Ile164 heterozygotes; and 38 and $320 \mathrm{bp}$ in Ile164 homozygotes.

\section{Fat cell lipolysis experiments}

Isolated fat cells were prepared and incubated as described in detail elsewhere (22). In brief, diluted suspensions $(0.2 \mathrm{ml})$ of isolated fat cells $(5,000-10,000$ cells $/ \mathrm{ml})$ were incubated in duplicate for $2 \mathrm{~h}$ in the presence or absence (basal) of increasing concentrations of the BAR-1 selective agonist dobutamine or the BAR-2 selective agonist terbutaline. We have demonstrated that these two agonists are selective for their designated receptors in isolated human abdominal subcutaneous fat cells (5). All incubations were performed at $37^{\circ} \mathrm{C}$ in KrebsHenseleit phosphate buffer ( $\mathrm{pH} 7.4)$, supplemented with glucose $(1 \mathrm{~g} / \mathrm{li}$ ter) and BSA ( $20 \mathrm{~g} /$ liter), using air as the gas phase. The ligands were added simultaneously at the start of the incubation. The concentrations used ranged from $10^{-12}$ to $10^{-4} \mathrm{~mol} /$ liter. Glycerol release to the incubation medium after the 2-h incubation was determined using an automated bioluminescence assay (23) and was used as a measurement of the lipolysis rate, since this metabolite is not reused by human fat cells to any significant extent. Both agonists caused a dose-dependent increase of glycerol release that always reached a plateau at the highest agonist concentrations. The sensitivity to agonist action was defined as the $\mathrm{pD}_{2}$ value, i.e., the negative logarithm of the $\mathrm{EC}_{50}$ value. The latter was defined as the concentration of each agonist giving a half-maximal effect. These $\mathrm{EC}_{50}$ values (expressed as log mol/liter) were determined by linear regression analysis after log-logit transformation of the ascending part of the individual concentration-response curves. They reflect specific agonist-receptor interactions, since at this concentration the selective agonists have few, if any, interactions with other adrenoceptor subtypes (24). Lipolysis rates in the presence or absence of maximum effective agonist concentrations were expressed relative to grams of lipid or incubated cell number. The methods for lipid extraction and calculation of adipocyte cell volume and number have been described in detail previously (22).

\section{Fat cell binding experiments}

These experiments could only be performed in a limited number of subjects because they required very large amounts of fat cells. The BAR-1/BAR-2 binding experiments were performed as described previously (22). In brief, the nonselective BAR antagonist ${ }^{125} \mathrm{I}$-cyanopindolol was used in saturation and displacement experiments. Fat cells were incubated for $60 \mathrm{~min}$, in a concentration of $\sim 20,000 \mathrm{cells} / \mathrm{ml}$, at $37^{\circ} \mathrm{C}$ in $0.5 \mathrm{ml}$ of KRP buffer, $\mathrm{pH} 7.4$, with bovine albumin $(5 \mathrm{~g} / \mathrm{li}$ ter), glucose $(1 \mathrm{~g} /$ liter $)$, and ascorbic acid $(0.1 \mathrm{~g} /$ liter $)$.

In the saturation experiments, the fat cells were incubated with $10,50,100,250,500$, and $750 \mathrm{pmol} / \mathrm{liter}$ of ${ }^{125} \mathrm{I}$-cyanopindolol. Nonspecific binding was determined by addition of propanolol $(0.1 \mu \mathrm{mol} /$ liter). In the displacement experiments, ${ }^{125}$ I-cyanopindolol binding (100 pmol/liter) was displaced by the highly selective BAR-2 antagonist ICI 118,551 in 12 increasing concentrations $\left(0,10^{-11}-10^{-4} \mathrm{~mol} / \mathrm{li}\right.$ - 
ter). Nonspecific binding was determined in the presence of $10^{-4} \mathrm{~mol} /$ liter of ICI 118,551.

The saturation experiments were evaluated by linear regression analysis of Scatchard plots giving an estimate of the total number of binding sites. The Scatchard plots were always linear. The displacing ligand ICI 118,551 binds to BAR-2 with high affinity and to BAR-1 with low affinity. Using a nonlinear least-squares regression analysis of the displacement curves, it was possible to determine the proportion of binding sites with high (BAR-2) and low affinity (BAR-1) for the displacing ligand, respectively.

As discussed in detail (22), the concentrations of ${ }^{125}$ I-cyanopindolol used here are not sufficiently high to identify BAR-3 binding sites.

\section{Drugs and chemicals}

The PCR kit and the restriction enzyme ItaI were purchased from Boehringer-Mannheim (Mannheim, Germany) and the ultra-pure DNA grade agarose from BIO-RAD (Hercules, CA). The restriction enzymes BsrDI and MnlI came from New England Biolabs Inc. (Beverly, MA) and the Meta-Phor agarose from FMC Bioproducts (Rockland, ME). BSA (fraction V) and propanolol were obtained from Sigma Chemical Co. (St. Louis, MO). Terbutaline sulfate came from Draco (Lund, Sweden), dobutamine hydrochloride from Eli Lilly \& Co. (Indianapolis, IN), ${ }^{125}$ I-cyanopindolol from DuPont/New England Nuclear (Boston, MA), and ICI 118,551 from Cambridge Research Biochemicals Ltd. (Cheshire, UK).
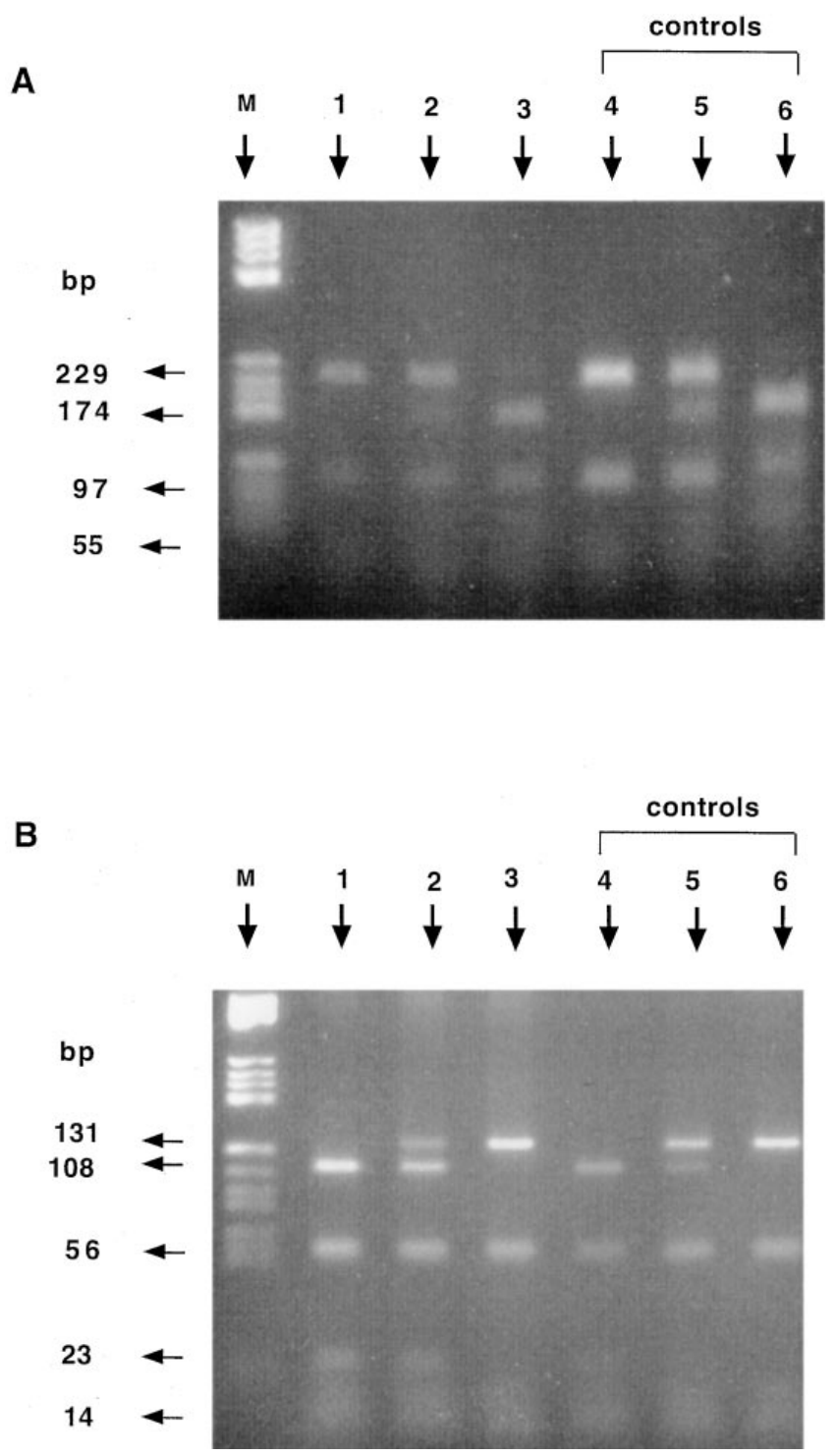

C

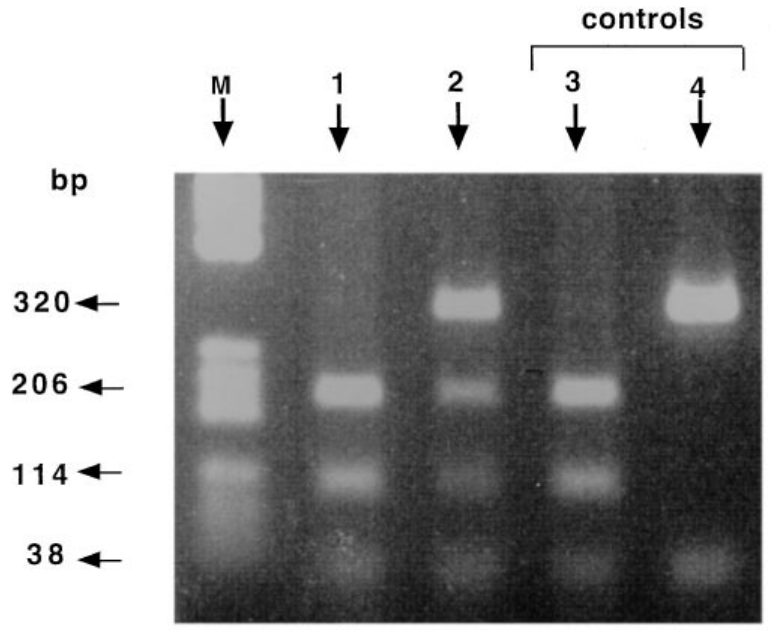

D

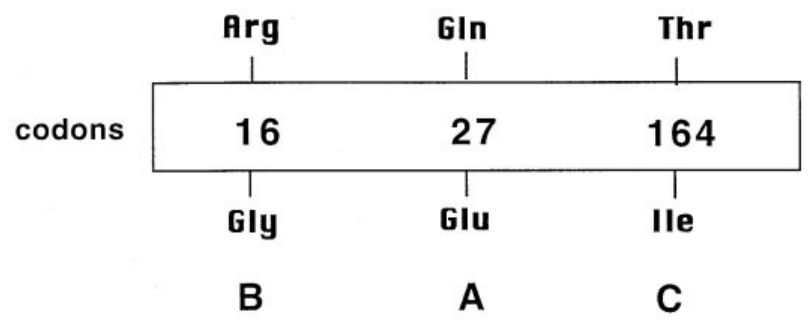

Figure 1. Detection of Gln27Glu $(A)$, Arg16Gly $(B)$, Thr164Ile $(C)$ polymorphisms of the BAR-2 by PCR and analysis of RFLP. $(A)$ The PCR products ( $353 \mathrm{bp}$ ) were digested with the restriction enzyme Ita I and visualized by staining with ethidium bromide. $M$, Molecular mass marker; lane 1, Glu27 homozygote; lane 2, Glu27Gln27 heterozygote; lane 3, Gln27 homozygote; lanes 4-6, control DNA for lanes 1-3, respectively.

$(B)$ The PCR products (201 bp) were digested with the restriction enzyme BsrDI and visualized by staining with ethidium bromide. $M$, Molecular mass marker; lane 1, Gly16 homozygote; lane 2, Gly16Arg16 heterozygote; lane 3, Arg16 homozygote; lanes 4-6, control DNA for lanes 1-3, respectively. $(C)$ The PCR products $(358 \mathrm{bp}$ ) were digested with the restriction enzyme MnlI and visualized by staining with ethidium bromide. $M$, Molecular mass marker; lane 1, Thr164 homozygote; lane 2, Thr164lle164 heterozygote; lane 3, control DNA for lane 1; lane 4, control DNA: Ile164 homozygote. $(D)$ Summary of BAR-2 polymorphism in codons 16, 27, and 164. 


\section{Statistical analysis}

Values are given as the mean \pm SEM. Statistical analysis was performed using Student's unpaired $t$ test, the $\chi^{2}$ test, and ANOVA. Relative risk and odds ratio were calculated as described previously (25). Relative risk $(\mathrm{R})$ is

$R=\frac{n_{1}\left(n_{2}+n_{4}\right)}{n_{2}\left(n_{1}+n_{3}\right)}$

and the odds ratio $(\mathrm{Ri})$ is

$R_{1}=\frac{n_{1} n_{4}}{n_{2} n_{3}}$

where $n_{1}$ is the number of patients with the characteristic, $n_{2}$ is the number of control individuals with the characteristic, and $n_{3}$ and $n_{4}$ are the corresponding numbers without the characteristic.

\section{Results}

RFLP. Representative RFLP analyses of the genetic variants in codons 16,27 , and 164 of the human BAR-2 are shown in Fig. 1. A distinct pattern was found for each of the polymorphisms. The patterns obtained were identical to parallel examination of control DNA from other subjects carrying the different polymorphisms (genotyped by Dr. Liggett and Dr. Hall). Furthermore, identical results were obtained when samples were genotyped by two of the investigators independently. For codons 16 and 27, all known genetic variants were found, i.e., homozygous for Arg16 or Gly16, heterozygous Arg16Gly16, homozygous for Gln27 or Glu27, and heterozygous Gln27Glu27. For codon 164, only homozygous for Thr164 and heterozygous Thr164Ile164 were found.

To confirm the determination of the genotype at codons 16 and 27, the PCR products from randomly chosen subjects with the three different genotypes for both mutations were submitted to automatic direct DNA sequencing (Cybergene, Stockholm, Sweden). The data obtained by sequencing were in accordance with our results (data not shown).

$B A R-2$ genotypes of obese and nonobese women. Genotyping of BAR-2 was performed on DNA from all 140 subjects to delineate polymorphisms in amino acids 16,27 , and 164 . The Thr164Ile variant occurred in only five subjects. Due to the very low polymorphic frequency at this locus, codon 164 was not considered further.

Polymorphisms in codon 27 had a very strong association with obesity (Tables I and II). The clustering of Glu27 with obesity was highly statistically significant by $\chi^{2}$ analysis $(P=$ 0.003 ) with an odds ratio as high as $10.4 ; 24 \%$ of the obese but only $3 \%$ of the nonobese subjects carried the homozygous form of Glu27, giving a sevenfold difference in frequency. In addition, the relative risk of being obese with the homozygous Glu27 genotype was 7. The frequency of each allele for the two polymorphisms also differed at a highly significant level between obese and nonobese subjects ( $P=0.004$ by $\chi^{2}$ analysis). Only homozygosity for Gln27 was significantly associated with obesity. The heterozygotes had an odds ratio of 1.3 , not statistically significant different from 1.0. In the whole material, homozygosity for Gly16 occurred in $49 \%$ of the subjects, as compared with $19 \%$ for Arg16 homozygosity. When the expected number of subjects in each group was calculated according to Hardy Weinberg, there should have been five homozygotes carrying Glu27Glu27 in the nonobese group. However, only
Table I. Distribution of the BAR-2 Gene Polymorphisms in Codons $16(A)$ and $27(B)$ and the Different Combinations of Codons 16 and $27(C)$

\begin{tabular}{|c|c|c|c|c|}
\hline Genotype & $\begin{array}{l}\text { Obese } \\
\text { subjects }\end{array}$ & $\begin{array}{l}\text { Nonobese } \\
\text { subjects }\end{array}$ & $P$ value & $\begin{array}{l}\text { Odds } \\
\text { ratio }\end{array}$ \\
\hline & $n$ & $n$ & & \\
\hline \multicolumn{5}{|l|}{ (A) } \\
\hline Gly16Gly16 & 37 & 31 & & 1.1 \\
\hline Gly16Arg16 & 31 & 14 & 0.228 & 2.1 \\
\hline $\begin{array}{l}\operatorname{Arg} 16 \operatorname{Arg} 16 \\
\text { (B) }\end{array}$ & 14 & 13 & & 1.0 \\
\hline Glu27Glu27 & 20 & 2 & & 10.4 \\
\hline Glu27Gln27 & 38 & 31 & 0.003 & 1.3 \\
\hline $\begin{array}{l}\mathrm{G} \ln 27 \mathrm{G} \ln 27 \\
\text { (C) }\end{array}$ & 24 & 25 & & 1.0 \\
\hline $\begin{array}{l}\operatorname{Arg} 16 \operatorname{Arg} 16 \\
\text { and } \mathrm{Gln} 27 \mathrm{G} \ln 27\end{array}$ & 12 & 13 & & 1.0 \\
\hline $\begin{array}{l}\text { Gly16Gly16 } \\
\text { and Glu27Glu27 }\end{array}$ & 19 & 2 & & 10.3 \\
\hline $\begin{array}{l}\text { Gly16Arg16 } \\
\text { and Glu27Gln27 }\end{array}$ & 27 & 21 & 0.024 & 1.4 \\
\hline $\begin{array}{l}\text { Gly16Gly16 } \\
\text { and Glu27Gln27 }\end{array}$ & 10 & 10 & & 1.1 \\
\hline $\begin{array}{l}\text { Gly16Arg16 } \\
\text { and } G \ln 27 \mathrm{G} \ln 27\end{array}$ & 10 & 10 & & 1.1 \\
\hline Other combinations & 4 & 2 & & \\
\hline
\end{tabular}

Values were compared by $\chi^{2}$ analysis. $n$, Number of subjects.

two carriers of that polymorphism were found. We have no clear explanation for this deficit. It might be due to the use of two different populations. In the subgroup of 55 women undergoing elective surgery, the expected number of nonobese subjects who were homozygous for Glu27 was 1 according to Hardy Weinberg. We found none, which did not differ from the expected number in a statistically significant way.

The combined polymorphisms at codons 16 and 27 were also examined (Table I). It was evident that the genetic variability in these two codons was in strong linkage disequilibrium, since $64 \%$ of the subjects carried both Gly16 and Glu27 in homozygous or heterozygous forms. The pattern of polymorphisms at both codons 16 and 27 differed significantly between the obese and nonobese subjects $\left(P=0.024\right.$ by $\chi^{2}$ analysis). However, the only major difference in frequency between both groups was a marked overrepresentation of both Gly16 and Glu27 homozygosity in the obese subjects, with an odds

Table II. Allele Frequency of BAR-2 Gene Polymorphisms in Codons 16 and 27

\begin{tabular}{lccc}
\hline Allele & Obese subjects & Nonobese subjects & $P$ value \\
\hline & $n$ & $n$ & \\
Gly16 & $105(64 \%)$ & $76(66 \%)$ & 0.446 \\
Arg16 & $59(36 \%)$ & $40(34 \%)$ & \\
Glu27 & $78(48 \%)$ & $35(30 \%)$ & 0.004 \\
Gln27 & $86(52 \%)$ & $81(70 \%)$ & \\
\hline
\end{tabular}

Values were compared by $\chi^{2}$ analysis. $n$, Number of alleles. 
Table III. Stratified Analysis of the Distribution of the BAR-2 Gene Polymorphisms in Codon $16(A)$ in Subjects Carrying $\left(\right.$ Glu $\left.27^{+}\right)$or Not $\left(\right.$Glu27 $7^{-}$) a Glutamic Acid at Codon 27, and Polymorphisms in Codon 27 (B) in Subjects Carrying

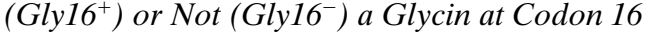

\begin{tabular}{lccc}
\hline & Obese subjects & Nonobese subjects & $P$ value \\
\hline & $n$ & $n$ & \\
(A) Glu27 & & & \\
Gly16Gly16 & 29 & 12 & 0.205 \\
Gly16Arg16 & 27 & 21 & \\
Arg16Arg16 & 2 & 0 & \\
Glu27- & & & \\
Gly16Gly16 & 2 & 2 & \\
Gly16Arg16 & 10 & 10 & \\
Arg16Arg16 & 12 & 13 & \\
(B) Gly16 & & & \\
Glu27Glu27 & 18 & 2 & \\
Glu27Gln27 & 36 & 31 & \\
Gln27Gln27 & 12 & 12 & \\
Gly16 & & & \\
Glu27Glu27 & 2 & 0 & \\
Glu27Gln27 & 2 & 0 & \\
Gln27Gln27 & 12 & 13 & \\
\hline
\end{tabular}

Values were compared by $\chi^{2}$ analysis. $n$, Number of subjects.

ratio as high as $10.3 .23 \%$ of the obese subjects carried this genetic variant, as compared with only $3 \%$ of the nonobese subjects, thus giving a sevenfold difference in frequency.

To further evaluate the relative importance of the polymorphism at codon 27 for obesity, we made a stratified analysis (Table III). First, we divided the samples into Glu $27^{+}$ (Glu27Glu27 and Glu27Gln27) and Glu27- (Gln27Gln27). Then we examined the effect of the Arg16 variant on obesity. Neither in Glu $27^{+}$nor in Glu27- subjects did the codon 16 polymorphism associate in a significant way with obesity. Second, we divided the samples into Gly16 ${ }^{+}$(Gly16Gly16 and Gly16Arg16) and Gly16- (Arg16Arg16). Then we examined the effect of the codon 27 variation on obesity. In Gly $16^{+}$carriers, there was a highly significant correlation between the codon 27 polymorphism and obesity $(P=0.009)$. A tendency for the same association was observed in Gly $16^{-}$carriers but the $P$ value did not reach a statistical significance. It may be due to the low number of total subjects since only 29 subjects were Gly16-.

Phenotypic characteristics of different polymorphisms in codons 16 and 27. The phenotypic characteristics of the polymorphisms in codon 27 are shown in Table IV. As depicted, the Gln27Glu polymorphisms were not associated with any alteration in BAR-1 or BAR-2 function. However, Glu27 homozygotes had, on average, $50 \%$ larger fat cells and $7 \mathrm{~kg} / \mathrm{m}^{2}$ higher BMI than homozygotes for Gln27. Homozygosity for Glu27 was associated with an excess of $\sim 20 \mathrm{~kg}$ in body fat, as compared with noncarriers. The Glu27 homozygotes had a higher fasting plasma insulin level than the Gln27 homozygotes $(P=0.03)$ and showed signs of an upper body fat distribution (i.e., increased WHR). BMI, body fat, fat cell volume, WHR, and insulin showed slightly higher values for the Glu27 homozygotes than for the Gln27Glu27 heterozygotes. However the differences did not reach a statistically significant level.

Table $\mathrm{V}$ shows the phenotypes of the codon 16 polymorphisms. The genetic variants did not differ statistically in BMI or in any other clinical parameters. However, homo- or heterozygosity for Gly in codon 16 was associated with a clear alteration of adipocyte BAR-2 function. This is illustrated by the mean values for terbutaline action; the $\mathrm{pD}_{2}$ value (representing agonist affinity for the receptor) was 0.6-0.7 log units higher in Gly16 homozygotes and in Arg16Gly16 heterozygotes, as compared with Arg16 homozygotes. This implies that mean terbutaline sensitivity was fivefold higher in adipocytes from the two former groups. This is further illustrated in Fig. 2 which shows representative concentration-response curves for the selective BAR-2 agonist terbutaline (three Gly16 homozygotes and three Arg16 homozygotes). The Gly16 homozygote curves were shifted to the left as compared with the Arg16 homozygote curves, indicating that the two polymorphisms differed in terbutaline sensitivity. Fig. 2 also shows the concentration-response curves obtained with the BAR-1 selective agonist dobutamine, for the representative three Arg16 and three Gly16 homozygotes. Unlike terbutaline, there were no clear differences between the dobutamine curves, nor did the mean values for dobutamine $\mathrm{pD}_{2}$ differ between the codon 16 polymorphic groups. There were no statistical differences in the maximum lipolytic action of either drug between the three genotypes, neither when lipolysis was expressed per gram of lipid nor per cell (i.e., $\mu$ mol glycerol $/ 10^{6}$ cells $/ 2 \mathrm{~h}$ ). The latter values for terbutaline-induced lipolysis in Arg16 homozygotes, Arg16Gly16 heterozygotes, and Gly16 homozygotes were $2.6 \pm 0.2,3.2 \pm 0.2$, and $2.8 \pm 0.2$, respectively, and did not differ significantly.

BAR binding was determined in 48 subjects. Maximum

Table IV. Phenotypic Characteristics of BAR-2 Gene Polymorphisms in Codon 27

\begin{tabular}{|c|c|c|c|c|c|}
\hline & \multirow{2}{*}{$\begin{array}{c}\text { (A) } \\
\text { Gln/Gln }\end{array}$} & \multirow{2}{*}{$\begin{array}{c}\text { (B) } \\
\text { Gln/Glu }\end{array}$} & \multirow{2}{*}{$\begin{array}{c}\text { (C) } \\
\text { Glu/Glu }\end{array}$} & \multicolumn{2}{|c|}{$P$ value } \\
\hline & & & & A vs. B & A vs. $C$ \\
\hline$n$ & 49 & 69 & 22 & & \\
\hline Age, yr & $38 \pm 2$ & $40 \pm 1$ & $36 \pm 2$ & NS & NS \\
\hline BMI, $\mathrm{kg} / \mathrm{m}^{2}$ & $30.7 \pm 1.5$ & $31.7 \pm 1.1$ & $38.2 \pm 1.8$ & NS & 0.004 \\
\hline Body fat, kg & $35.9 \pm 4.2$ & $36.6 \pm 3.3$ & $55.5 \pm 5.8$ & NS & 0.009 \\
\hline Fat cell volume, pl & $574 \pm 34$ & $659 \pm 29$ & $842 \pm 42$ & NS & 0.001 \\
\hline WHR & $0.89 \pm 0.01$ & $0.91 \pm 0.01$ & $0.95 \pm 0.01$ & NS & 0.002 \\
\hline $\mathrm{p}$-glucose, $\mathrm{mmol} / \mathrm{liter}$ & $5.1 \pm 0.1$ & $5.4 \pm 0.1$ & $5.3 \pm 0.2$ & NS & NS \\
\hline p-insulin, mU/liter & $10.6 \pm 0.9$ & $12.3 \pm 1.1$ & $14.7 \pm 2.0$ & NS & 0.034 \\
\hline $\mathrm{pD}_{2}$ Terbutaline & $7.4 \pm 0.2$ & $7.6 \pm 0.2$ & $7.7 \pm 0.2$ & NS & NS \\
\hline $\mathrm{pD}_{2}$ Dobutamine & $7.8 \pm 0.2$ & $7.6 \pm 0.1$ & $7.8 \pm 0.1$ & NS & NS \\
\hline $\begin{array}{l}\text { Glycerol release } \\
\mu \mathrm{mol} / \mathrm{g} \text { lipid } / 2 \mathrm{~h}:\end{array}$ & & & & & \\
\hline Basal & $1.2 \pm 0.1$ & $1.2 \pm 0.1$ & $1.5 \pm 0.1$ & NS & NS \\
\hline Terbutaline & $5.6 \pm 0.4$ & $5.4 \pm 0.3$ & $4.4 \pm 0.3$ & NS & NS \\
\hline Dobutamine & $5.4 \pm 0.4$ & $5.1 \pm 0.3$ & $4.5 \pm 0.3$ & NS & NS \\
\hline
\end{tabular}

Values are mean \pm SEM. They were compared by Student's unpaired $t$ test. $n$, Number of subjects; $p$, fasting plasma; $p D_{2}$, minus $\log$ value for half-maximal effective concentration. 
Table V. Phenotypic Characteristics of BAR-2 Gene Polymorphisms in Codon 16

\begin{tabular}{|c|c|c|c|c|c|}
\hline & & & & $P \mathrm{v}$ & alue \\
\hline & Arg/Arg & Arg/Gly & Gly/Gly & A vs. $\mathrm{B}$ & A vs. C \\
\hline$n$ & 27 & 45 & 68 & & \\
\hline Age, yr & $37 \pm 2$ & $39 \pm 1$ & $38 \pm 2$ & NS & NS \\
\hline BMI, $\mathrm{kg} / \mathrm{m}^{2}$ & $31.4 \pm 2.0$ & $31.3 \pm 1.1$ & $34.6 \pm 1.4$ & NS & NS \\
\hline Body fat, $\mathrm{kg}$ & $34.9 \pm 5.3$ & $37.8 \pm 3.5$ & $36.6 \pm 4.4$ & NS & NS \\
\hline Fat cell volume, pl & $604 \pm 47$ & $649 \pm 28$ & $703 \pm 41$ & NS & NS \\
\hline WHR & $0.91 \pm 0.01$ & $0.90 \pm 0.01$ & $0.93 \pm 0.01$ & NS & NS \\
\hline p-glucose, $\mathrm{mmol} /$ liter & $5.2 \pm 0.1$ & $5.2 \pm 0.1$ & $5.4 \pm 0.1$ & NS & NS \\
\hline p-insulin, mU/liter & $11.0 \pm 1.1$ & $11.6 \pm 0.8$ & $13.6 \pm 1.6$ & NS & NS \\
\hline $\mathrm{pD}_{2}$ Terbutaline & $7.0 \pm 0.2$ & $7.6 \pm 0.2$ & $7.7 \pm 0.2$ & 0.028 & 0.027 \\
\hline $\mathrm{pD}_{2}$ Dobutamine & $7.6 \pm 0.2$ & $7.7 \pm 0.1$ & $7.8 \pm 0.1$ & NS & NS \\
\hline Glycerol release & & & & & \\
\hline$\mu \mathrm{mol} / \mathrm{g}$ lipid$/ 2 \mathrm{~h}:$ & & & & & \\
\hline Basal & $1.1 \pm 0.1$ & $1.4 \pm 0.1$ & $1.2 \pm 0.1$ & NS & NS \\
\hline Terbutaline & $5.3 \pm 0.5$ & $5.7 \pm 0.3$ & $4.6 \pm 0.3$ & NS & NS \\
\hline Dobutamine & $5.2 \pm 0.5$ & $5.5 \pm 0.3$ & $4.5 \pm 0.3$ & NS & NS \\
\hline
\end{tabular}

Values are mean \pm SEM. They were compared by Student's unpaired $t$ test. $n$, Number of subjects; $p$, fasting plasma; $p D_{2}$, minus log value for half-maximal effective concentration.

BAR-1 binding capacity (amol/10 cells) was $61.4 \pm 12.2,92.2 \pm$ 18.2, and $78.7 \pm 10.2$ for Arg16 homozygotes, Arg16Gly16 heterozygotes, and Gly16 homozygotes, respectively. These values did not differ significantly ( $F=0.58$ by ANOVA). Corresponding values for BAR-2 maximum binding were 53.2 \pm 10.4 , $72.9 \pm 23.2$, and $76.1 \pm 7.3$, respectively. There were no significant differences between these values either $(F=0.68$ by ANOVA). Moreover, there were no significant differences between the groups in regard to receptor affinities for the displacing drug ICI 118,551 or for the radioligand ${ }^{125}$ I-cyanopindolol (data not shown).

The effect on the phenotype of some of the combined polymorphisms in codons 16 and 27 is demonstrated in Table VI. It is apparent that in homozygotes for both Gly16 and Glu27, most of the phenotypic characteristics were similar to those observed when Gly16 and Gln27 homozygosities were investigated separately (Tables IV and V). Thus, they had significantly higher BMI, body fat, WHR, fat cell size, and $\mathrm{pD}_{2}$ for terbutaline than the homozygotes for both Arg16 and Gln27. We also investigated the contribution of codon 16 variants on the phenotype by comparing women who were homozygous for both $\operatorname{Arg} 16$ and Gln27 with women who were both heterozygous Gly16Arg16 and homozygous for Gln27. This latter phenotype was associated with a significant increase in terbutaline $\mathrm{pD}_{2}$, giving a fivefold increase in terbutaline sensitivity $(P<0.005)$. However, there were no statistically significant changes in any of the other investigated parameters. Unfortunately, it was not possible to investigate separately the phenotypic role of polymorphisms in codon 27 since only two subjects who carried the Glu27 variant were homozygous for Arg16.

Genotypic and phenotypic characteristics of a study subgroup. To investigate if the use of two populations had any important effect on the distribution of the BAR-2 polymor- phism in codons 16 and 27 or, on the phenotypic characteristics, we did a separate investigation on the 85 women undergoing biopsy under local anesthesia, since they formed the largest subgroup. The findings in this cohort were almost identical with those shown for the whole study population. The numbers of subjects carrying Glu27Glu27, Glu27Gln27, and Gln27Gln27 among the obese women were 12,25 , and 10 , respectively. The corresponding numbers for the nonobese women were 2, 21, and 15 . The difference between obese and nonobese subjects was statistically significant $(P=0.02)$. Obese Glu27 homozygotes had an odds ratio of 9.0 and the obese Glu27Gln27 subjects had an odds ratio of 1.8. On the other hand, there was no statistically significant association between the codon 16 polymorphism and obesity in this subgroup (data not shown).

We also examined the phenotypic characteristics of the cohort. Glu27Glu27 was associated with a statistically significant increase in BMI, WHR, body fat, fat cell volume, and plasma insulin as compared with Gln27Gln27, but there was no difference between the two genotypes in regard to BAR agonist sensitivity. The codon 16 polymorphism did not influence the values for BMI, WHR, body fat, fat cell volume, and plasma
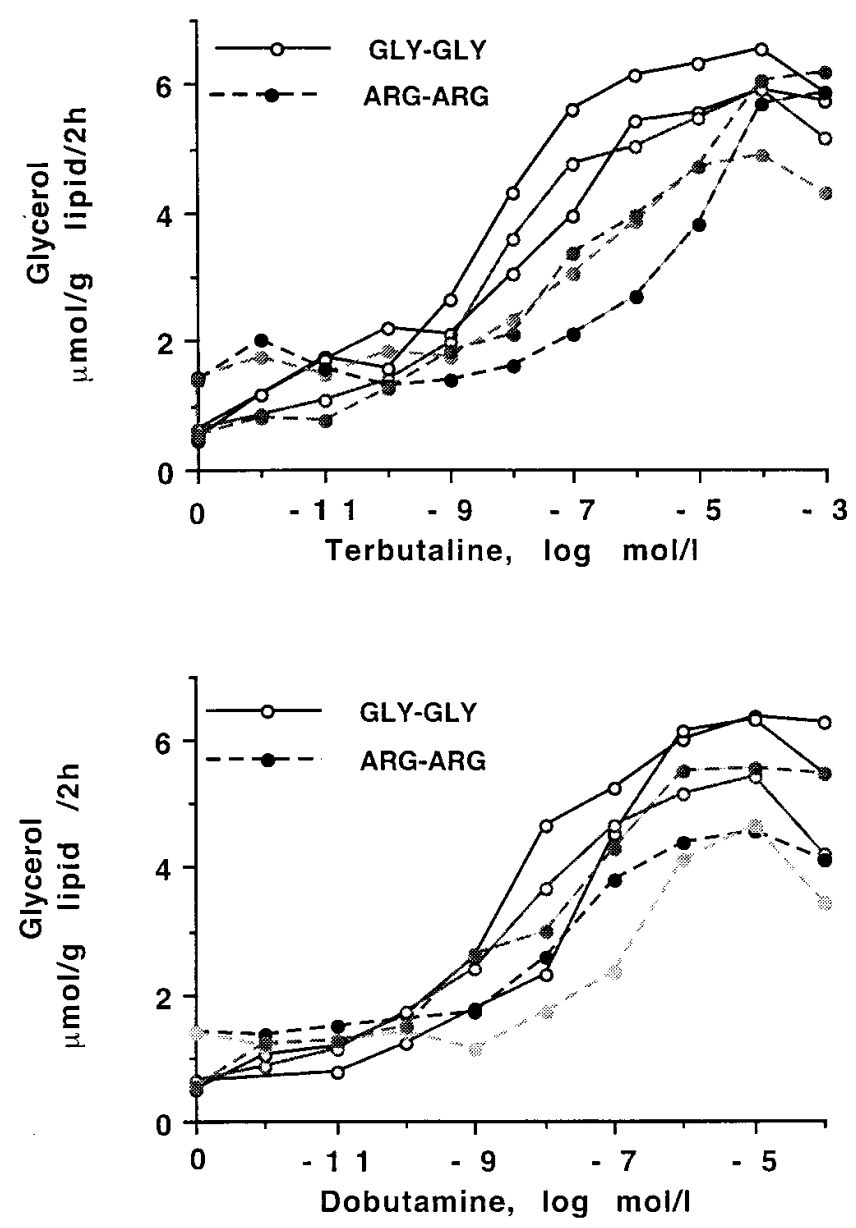

Figure 2. Codon 16 BAR-2 polymorphism and lipolysis. Concentration-response curves for terbutaline (top) and dobutamine (bottom) induced glycerol release. Fat cells were incubated in the absence and presence of increasing concentrations of the BAR-1 or the BAR-2 selective agonist. Three representative homozygous Gly16 subjects and three representative homozygous Arg16 subjects are depicted. 
Table VI. Phenotypic Characteristics of Combined Polymorphisms in Codons 16 and 27 of the BAR-2 Gene

\begin{tabular}{|c|c|c|c|c|c|}
\hline & \multirow{2}{*}{$\begin{array}{c}\text { (A) } \\
\text { Arg16Arg16 } \\
\text { Gln27Gln27 }\end{array}$} & \multirow{2}{*}{$\begin{array}{c}\text { (B) } \\
\text { Gly16Gly16 } \\
\text { Glu27Glu27 }\end{array}$} & \multirow{2}{*}{$\begin{array}{c}\text { (C) } \\
\text { Gly16Arg16 } \\
\text { Gln27Gln27 }\end{array}$} & \multicolumn{2}{|c|}{$P$ value } \\
\hline & & & & A vs. B & A vs. $\mathrm{C}$ \\
\hline$n$ & 25 & 21 & 20 & & \\
\hline Age, yr & $38 \pm 2$ & $37 \pm 2$ & $39 \pm 3$ & NS & NS \\
\hline BMI, $\mathrm{kg} / \mathrm{m}^{2}$ & $30.6 \pm 2.0$ & $37.6 \pm 1.8$ & $30.6 \pm 2.4$ & 0.013 & NS \\
\hline Body fat, $\mathrm{kg}$ & $33.2 \pm 5.0$ & $53.7 \pm 5.8$ & $31.2 \pm 4.0$ & 0.008 & NS \\
\hline Fat cell volume, pl & $604 \pm 51$ & $848 \pm 43$ & $569 \pm 51$ & 0.001 & NS \\
\hline WHR & $0.90 \pm 0.02$ & $0.95 \pm 0.01$ & $0.88 \pm 0.02$ & 0.024 & NS \\
\hline $\mathrm{p}$-glucose, $\mathrm{mmol} /$ liter & $5.2 \pm 0.1$ & $5.3 \pm 0.2$ & $5.0 \pm 0.1$ & NS & NS \\
\hline p-insulin, mU/liter & $11.0 \pm 1.2$ & $14.7 \pm 2.2$ & $9.8 \pm 1.2$ & NS & NS \\
\hline $\mathrm{pD}_{2}$ Terbutaline & $7.0 \pm 0.2$ & $7.7 \pm 0.3$ & $7.7 \pm 0.3$ & 0.032 & 0.033 \\
\hline $\mathrm{pD}_{2}$ Dobutamine & $7.6 \pm 0.2$ & $7.7 \pm 0.2$ & $7.9 \pm 0.2$ & NS & NS \\
\hline $\begin{array}{l}\text { Glycerol release } \\
\mu \mathrm{mol} / \mathrm{g} \text { lipid } / 2 \mathrm{~h}:\end{array}$ & & & & & \\
\hline Basal & $1.1 \pm 0.1$ & $1.4 \pm 0.1$ & $1.3 \pm 0.2$ & NS & NS \\
\hline Terbutaline & $5.4 \pm 0.6$ & $4.5 \pm 0.3$ & $6.0 \pm 0.4$ & NS & NS \\
\hline Dobutamine & $5.2 \pm 0.6$ & $4.5 \pm 0.3$ & $5.8 \pm 0.5$ & NS & NS \\
\hline
\end{tabular}

Values are mean \pm SEM. They were compared by Student's unpaired $t$ test. $n$, Number of subjects; $p$, fasting plasma; $p D_{2}$, minus $\log$ value for half-maximal effective concentration.

insulin in a statistically significant way. Gly16Gly16 was associated with a statistically significant increase in terbutaline sensitivity in comparison with Arg16Arg16. However, no differences in dobutamine sensitivity between the latter two genotypes were found.

\section{Discussion}

To the best of our knowledge, this study is the first to demonstrate a gene polymorphism that is strongly overrepresented in human obesity and that has a marked influence on body fat content. Another novel observation is that a common coding mutation in the human BAR-2 gene affects receptor function in a native target cell such as the adipocyte.

Substitution of Gln for Glu in both alleles at codon 27 of the BAR-2 gene had a marked association with obesity; the odds ratio was as high as 10.4. The Glu27 homozygotes had $\sim 20 \mathrm{~kg}$ of excess body fat and a $50 \%$ increase in fat cell size, as compared with Gln 27 homozygotes. They had also signs of an upper body type of obesity and insulin resistance. For all the traits for which Glu27 homozygotes differed from Gln27 homozygotes, however, the Glu27Gln27 heterozygotes had an intermediate value which was not statistically significant. This might suggest that there is also an effect of the heterozygosity on obesity; however, it does not attain significance at the current sample size. Noncarriers were also slightly obese with a mean BMI of $\sim 30 \mathrm{~kg} / \mathrm{m}^{2}$. Therefore, this latter group might have also some obesity-associated abnormalities in the clinical measures. Further studies on population-based cohorts are needed to determine whether the Gln27Glu polymorphism in the BAR-2 gene is of importance for obesity-mediated complications. No difference in BAR-2 function between carriers and noncarriers of Glu27 was observed. However, it is not possible to state whether the latter is more apparent than real, since ge- netic variability in codons 16 and 27 were in linkage disequilibrium, as discussed below. Therefore, it is not known at present how Glu27 can promote obesity. Anyhow, it appears that the Gln27Glu polymorphism is an important genetic marker for human obesity, since it is highly overrepresented in overweight women ( $24 \%$ as compared with $3 \%$ in controls) and the relative risk of being obese in subjects homozygous for Glu27 is as high as 7.

The codon 16 polymorphism seems to be of marked importance for BAR-2 function, at least in fat cells, but less so for obesity. The polymorphism in codon 16 was not associated with any statistically significant variation in obesity variables. However, carriers with one or two Gly16 alleles had a fivefold increased agonist BAR-2 affinity. According to classical drug receptor theories (24), a change in agonist $\mathrm{pD}_{2}$ but with a preserved maximum effect indicates an alteration at the receptor level and not downstream in signal transduction in a spare receptor system such as the human adipocyte BAR (26). However, judging from the results of the radioligand binding experiments, there was no evidence of an important effect of the polymorphism on BAR-2 expression. Therefore, we assume that a substitution of arginine for glycine at codon 16 in the human BAR-2 enhances affinity and/or coupling of the receptor, at least in fat cells. It was not possible to explore the molecular mechanism for such Gly16-associated changes in receptor function because of the limited amount of fat tissue that was available. It should be noted that BAR-2 in recombinant cells expressing Gly16 has an increased sensitivity to long-term agonist-mediated receptor downregulation (15). It is possible that the native human genotype also carries this feature, which is then characterized by increased agonist affinity in the "resting" state presently investigated. Since heterozygotes and homozygotes showed the same change, it appears that Gly16 dominates over Arg16 in BAR-2 function.

The polymorphisms in codons 16 and 27 were in a strong linkage disequilibrium, as two-thirds of the women carried at the same time Gly16 and Gln27 in a hetero- or homozygous form. Homozygotes for both Gly16 and Glu27 had a $20 \mathrm{~kg}$ body fat excess, $50 \%$ enlarged fat cells, and fivefold increased BAR-2 agonist affinity in comparison with noncarriers. Furthermore, subjects who were homozygotes for Gly16 and heterozygotes for codon 27 had fivefold higher BAR-2 agonist affinity, but did not statistically differ in obesity variables when compared with those who were noncarriers at both loci. Therefore, it is tempting to speculate that the codon 27 variant in some way associates with obesity per se, whereas the codon 16 variant only modulates BAR-2 function. To further solidify the argument that codon 27 is primary for the effect on obesity, we also performed a stratified analysis. In Gly16 carriers, the codon 27 variant associated significantly with obesity $(P=$ $0.009)$. On the other hand, in Glu27 carriers, the codon 16 variant did not associate with obesity in a statistically significant way. This might further suggest that codon 27 has a primary effect on obesity.

To obtain a sufficiently large study group, we pooled data from two different cohorts, including women who were investigated by undergoing either a fat biopsy under local anesthesia or a fat biopsy during benign elective general surgery. We believe it is relevant to combine these two groups for several reasons. The "local anesthesia" women only varied in their relative body weight. The "elective surgery" women were either operated on for obesity or for nonendocrine disorders such as 
gallstones or hernias. Thus, the only major variation between subjects in the two groups was their relative body weight. A direct comparison of clinical variables between both groups did not reveal any differences. Furthermore, we have shown recently that when abdominal subcutaneous adipocytes were obtained from the same subjects, first under local anesthesia and later during general surgery, there were no statistical differences in adrenoceptor function nor in lipolysis when data from the two biopsy procedures were compared (20). Finally, when only the local anesthesia women were investigated, the results were essentially the same as for the whole study population.

Arg16 has been defined as the wild type, because this variant of the BAR-2 gene was the first to be cloned (27). However, homozygosity for Arg16 has been shown previously to be less common than homozygosity for the mutated Gly16 form (28). The same pattern was observed here; Arg16 homozygosity occurred in $19 \%$ of the subjects as compared with $33 \%$ for Gly16 homozygosity. It was demonstrated previously that homozygotes for wild-type Gln27 are much more common than homozygotes for Glu27 (20). This was also confirmed in this study; Gln27 homozygosity was about twice as common as homozygosity for Glu27 in the whole material.

Within the past $3 \mathrm{yr}$, all of the single-gene mutations resulting in rodent obesity have been cloned (29). In contrast, little progress has been made during the same period with respect to the genetic basis of human obesity, as recently reviewed (3). Most of the earlier association studies have been negative. In the rare positive ones, the sample size was small and the evidence weak. The earlier linkage studies have also been disappointing. This negative picture may now change. Using linkage analysis, a major quantitative trait locus determining fat mass has been found which is related to chromosome 2 (30). Our present study suggests that genes on chromosome 5 (probably the BAR-2 gene) also contribute to an important way to variations in fat mass and the regulation of the energy expenditure. However, our results are based on convenient samples. They need to be confirmed on population-based samples and also on other ethnic material. Furthermore, we investigated women only. The importance of genetic variability in BAR-2 for obesity and receptor function in men remains to be established.

In summary, this study shows that common polymorphisms in the BAR-2 gene are markedly associated with obesity and BAR-2 function. In the homozygous form, a Glu27 variant is very common in obesity and associates with increased body fat and enlarged fat cells. A Gly16 variant is above all associated with improved adipocyte BAR-2 function. Thus, genetic variability in the human BAR-2 gene could be of major importance for obesity and BAR-2 function in adipose tissue, at least in women.

\section{Acknowledgments}

The authors thank S. Liggett and I.P. Hall for sending DNA from several subjects with sequence proven BAR-2 polymorphism. The valuable advice of Charlotte Forsell regarding genotyping and the excellent technical assistance of Britt Marie Leijonhufvud, Catharina Hertel, Eva Sjölin, and Kerstin Wåhlen are greatly appreciated.

This study was supported by grants from the Swedish Medical Research Council, Swedish Diabetes Association, Swedish Medical Society, Swedish Heart and Lung Foundation, Commission of European Communities, INSERM, ALFEDIAM, the Swedish Institute, Karolinska Institute and the foundations of Novo Nordisk, Bergwall,
Söderberg, Old Female Servants, Hedlund, King Gustaf V and Queen Victoria, and Belvén.

\section{References}

1. Bouchard, C. 1996. Long-term programming of body size. Nutr. Rev. 54: S8-S16

2. Spiegelman, B.M., and J.S. Flier. 1996. Adipogenesis and obesity: rounding out the big picture. Cell. 87:377-389.

3. Bouchard, C., and L. Perusse. 1996. Current status of the human obesity gene map. Obesity Res. 4:81-90.

4. Lafontan, M., and M. Berlan. 1993. Fat cell adrenergic receptor and the control of white and brown fat cell function. J. Lipid Res. 34:1057-1091.

5. Enocksson, S., M. Shimizu, F. Lönnqvist, J. Nordenström, and P. Arner. 1995. Demonstration of an in vivo functional $\beta_{3}$-adrenoceptor in man. J. Clin. Invest. 95:2239-2245.

6. Barbe, P., L. Millet, J. Galitzki, M. Lafontan, and M. Berlan. 1996. In situ assessment of the role of beta1-, beta2-, and beta3-adrenoceptors in the control of lipolysis and nutritive blood flow in human subcutaneous adipose tissue. $\mathrm{Br}$. J. Pharmacol. 117:907-913.

7. Clement, K., C. Vaisse, B.J. Manning, A. Basdevant, B. Guy-Grand, J. Ruiz, K. Silver, A.R. Shuldiner, P. Froguel, and A.D. Strosberg. 1995. Genetic variation in the $\beta_{3}$-adrenergic receptor and an increased capacity to gain weight in patients with morbid obesity. N. Engl. J. Med. 333:352-354.

8. Walston, J., K. Silver, C.J. Bogardus, W. Knowler, F. Celi, S. Austin, B. Manning, D. Strosberg, P. Stern, N. Raben, J. Sorkin, J. Roth, and A.R. Shuldiner. 1995. Time of onset of non-insulin-dependent diabetes mellitus and genetic variation in the $\beta_{3}$-adrenergic-receptor gene. N. Engl. J. Med. 333:343-347.

9. Widén, E., M. Lehto, T.J. Kanninen, J. Walston, A.R. Shuldiner, and L.C. Groop. 1995. Association of a polymorphism in the $\beta_{3}$-adrenergic-receptor gene with features of the insulin resistance syndrome in Finns. N. Engl. J. Med. 333:348-351.

10. Sipilaïnen, R., M. Uusitupa, S. Heikkinen, A. Rissanen, and M. Laakso. 1997. Polymorphism of the $\beta_{3}$-adrenergic receptor gene affects basal metabolic rate in obese Finns. Diabetes. 46:77-80.

11. Gagnon, J., P. Mauriege, S. Roy, D. Sjöström, Y.C. Chagnon, F.T. Dionne, J.M. Oppert, L. Perusse, L. Sjöström, and C. Bouchard. 1996. The Trp64Arg mutation of the $\beta_{3}$-adrenergic receptor gene has no effect on obesity phenotype in the Quebec family study and Swedish obese subjects cohort. $J$. Clin. Invest. 98:2086-2093.

12. Fujisawa, T., H. Ikegami, E. Yamato, K. Takekawa, Y. Nakagawa, Y. Hamada, T. Oga, H. Ueda, M. Shintani, M. Fukuda, and T. Ogihara. 1996. Association of Trp64Arg mutation of the $\beta_{3}$-adrenergic-receptor with NIDDM and body weight gain. Diabetologia. 39:349-352.

13. Li, L.S., F. Lönnqvist, H. Luthman, and P. Arner. 1996. Phenotypic characterization of the Trp64Arg polymorphism in the beta3-adrenergic receptor gene in normal weight and obese subjects. Diabetologia. 39:857-860.

14. Candelore, M.R., L. Deng, L.M. Tota, L.J. Kelly, M.A. Cascieri, and C.D. Strader. 1996. Pharmacological characterization of a recently described human beta 3-adrenergic receptor mutant. Endocrinology. 137:2638-2641.

15. Green, S.A., J. Turki, I.P. Hall, and S.B. Liggett. 1995. Implications of genetic variability of human $\beta_{2}$-adrenergic receptor structure. Pulm. Pharmacol. 8:1-10.

16. Green, S.A., J.M. Turki, M. Innis, and S.B. Liggett. 1994. Amino-terminal polymorphisms of the human $\beta_{2}$-adrenergic receptor impart distinct agonist-promoted regulatory properties. Biochemistry. 33:9414-9419.

17. Green, S.A., G. Cole, M. Jacinto, M. Innis, and S.B. Liggett. 1993. A polymorphism of the human $\beta_{2}$-adrenergic receptor within the fourth transmembrane domain alters ligand binding and functional properties of the receptor. J. Biol. Chem. 268:23116-23121.

18. Liggett, S.B. 1995. Genetics of $\beta_{2}$-adrenergic receptor variants in asthma. Clin. Exp. Allergy. 25:89-94.

19. Turki, J., J. Pak, S.A. Green, R.J. Martin, and S.B. Liggett. 1995. Genetic polymorphisms of the $\beta_{2}$-adrenergic receptor in nocturnal and nonnocturnal asthma. J. Clin. Invest. 95:1635-1641.

20. Large, V., S. Reynisdottir, L. Eleborg, V. van Harmelen, L. Strömmer, and P. Arner. 1997. Lipolysis in human fat cells obtained under local and general anesthesia. Int. J. Obesity. 21:78-82.

21. Gallagher, D., M. Visser, D. Sepulveda, N. Pierson, T. Harris, and S.B. Heymsfield. 1995. How useful is body mass index for comparison of body fatness across age, sex, and ethnic groups. Am. J. Epidemiol. 143:228-239.

22. Reynisdottir, S., K. Ellerfeldt, H. Wahrenberg, H. Lithell, and P. Arner. 1994. Multiple lipolysis defects in the insulin resistance (metabolic) syndrome. J. Clin. Invest. 93:2590-2599.

23. Hellmer, J., P. Arner, and A. Lundin. 1989. Automatic luminometric kinetic assay of glycerol for lipolysis studies. Anal. Biochem. 177:132-137.

24. Kenakin, T. 1984. The classification of drugs and drug receptors in isolated tissue. Pharmacol. Rev. 36:165-214.

25. Ott, J. 1991. Analysis of Human Genetic Linkage. The Johns Hopkins University Press, Baltimore and London. 240-241.

26. Arner, P., J. Hellmer, A. Wennlund, J. Östman, and P. Engfeldt. 1988. 
Adrenoceptor occupancy in isolated human fat cells and its relationship with lipolysis rate. Eur. J. Pharmacol. 146:45-56.

27. Reihaus, E., M. Innis, N. MacIntyre, and S.B. Liggett. 1993. Mutations in the gene encoding for the $\beta_{2}$-adrenergic receptor in normal and asthmatic subjects. Am. J. Respir. Cell Mol. Biol. 8:334-339.

28. Kobilka, B.K., R.A.F. Dixon, T. Frielle, H.G. Dohlman, M.A. Bolanowski, I.S. Sigal, T.L. Yang-Feng, U. Francke, M.C. Caron, and F. Lefkowitz. 1987. cDNA for the human $\beta_{2}$-adrenergic receptor: a protein with multiple membrane-spanning domains and encoded by a gene whose chromosomal loca- tion is shared with that of the receptor for platelet-derived growth factor. Proc. Natl. Acad. Sci. USA. 84:46-50.

29. Streamson, C., and R.L. Leibel. 1997. Obesity genes: molecular and metabolic mechanisms. Diabetes Rev. 5:2-7.

30. Comuzzie, A.G., J.E. Hixson, L. Almasy, B.D. Mitchell, M.C. Mahaney, T.D. Dyer, M.P. Stern, J.W. MacCluer, and J. Blangero. 1997. A major quantitative trait locus determining serum leptin levels and fat mass is located on chromosome 2. Nat. Genet. 15:273-276. 